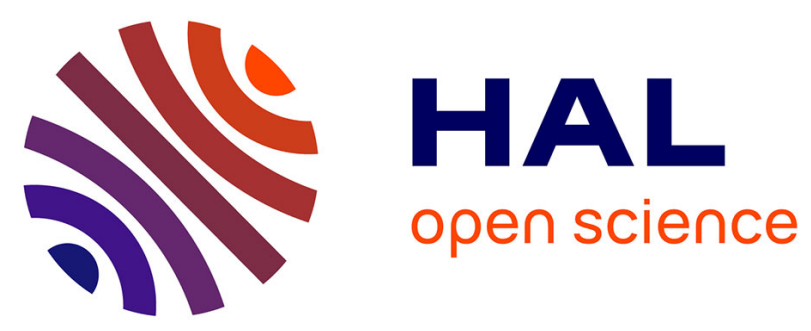

\title{
An oxidovanadium(IV) complex with 4,4'-di-tert-butyl-2,2'-bipyridine ligand: Synthesis, structure and catalyzed cyclooctene epoxidation
}

Iakov Fomenko, Sandrine Vincendeau, Eric Manoury, Rinaldo Poli, Pavel Abramov, Vladimir Nadolinny, Maxim Sokolov, Artem Gushchin

\section{To cite this version:}

Iakov Fomenko, Sandrine Vincendeau, Eric Manoury, Rinaldo Poli, Pavel Abramov, et al.. An oxidovanadium(IV) complex with 4,4'-di-tert-butyl-2,2'-bipyridine ligand: Synthesis, structure and catalyzed cyclooctene epoxidation. Polyhedron, 2020, 177, pp.114305. 10.1016/j.poly.2019.114305 . hal-02563748

\section{HAL Id: hal-02563748 \\ https://hal.science/hal-02563748}

Submitted on 17 Nov 2020

HAL is a multi-disciplinary open access archive for the deposit and dissemination of scientific research documents, whether they are published or not. The documents may come from teaching and research institutions in France or abroad, or from public or private research centers.
L'archive ouverte pluridisciplinaire HAL, est destinée au dépôt et à la diffusion de documents scientifiques de niveau recherche, publiés ou non, émanant des établissements d'enseignement et de recherche français ou étrangers, des laboratoires publics ou privés. 


\title{
An oxidovanadium(IV) complex with 4,4'-di-tert-butyl-2,2'- bipyridine ligand: synthesis, structure and catalyzed cyclooctene epoxidation
}

Iakov S. Fomenko, ${ }^{\mathrm{b}}$ Sandrine Vincendeau, ${ }^{\mathrm{a}}$ Eric Manoury, ${ }^{\mathrm{a}}$ Rinaldo Poli, ${ }^{\mathrm{a}, \mathrm{c},}$ Pavel A. Abramov, ${ }^{\mathrm{b}}$ Vladimir A. Nadolinny, ${ }^{\mathrm{b}}$ Maxim N. Sokolov, ${ }^{\mathrm{b}, \mathrm{d}}$ Artem L. Gushchin,,${ }^{\mathrm{b}, *}$

${ }^{a}$ CNRS, LCC (Laboratoire de Chimie de Coordination), Université de Toulouse, UPS, INPT, 205 Route de Narbonne, BP 44099, 31077 Toulouse, France.

${ }^{b}$ Nikolaev Institute of Inorganic Chemistry, Siberian Branch of Russian Academy of Sciences, 3 Acad. Lavrentiev Avenue, Novosibirsk 630090,Russia.E-mail: gushchin@niic.nsc.ru

${ }^{c}$ Institut Universitaire de France, 1 Rue Descartes, 75231 Paris Cedex 05, France.

${ }^{d}$ Novosibirsk State University, 2 Pirogov Street, 630090 Novosibirsk, Russia

* Corresponding author. E-mail: gushchin@ niic.nsc.ru (Artem L. Gushchin)

\begin{abstract}
The interaction of vanadium(III) chloride $\left(\mathrm{VCl}_{3}\right)$ with 4,4'-di-tert-butyl-2,2'-bipyridine (dbbpy) in air resulted in the monomeric oxidovanadium(IV) complex $\left[\mathrm{VOCl}_{2}(\mathrm{dbbpy})\left(\mathrm{H}_{2} \mathrm{O}\right)\right]$ (1) in high yield. The complex was characterized by IR and EPR spectroscopies, by elemental analysis, and by single crystal X-ray diffraction analysis. The vanadium atom has a distorted octahedral coordination environment. The EPR spectrum of 1 in $\mathrm{CH}_{2} \mathrm{Cl}_{2}$ demonstrates an eightline signal typical of vanadium(IV) with a $\mathrm{d}^{1}$ electronic configuration. Complex $\mathbf{1}$ exhibits catalytic activity in the cyclooctene oxidation with tert-butyl hydroperoxide (TBHP) in $\mathrm{CHCl}_{3}$. Detailed EPR, NMR and GC-MS studies of the reaction revealed a few mechanistic details and the nature of by-products that are generated by involvement of the chloroform solvent.
\end{abstract}

Keywords: oxidovanadium(IV) complexes; 2,2'-bipyridine ligands; crystal structure; EPR spectroscopy; cyclooctene epoxidation.

\section{Introduction}

Oxidovanadium complexes containing the $\mathrm{V}=\mathrm{O}$ moiety are nearly omnipresent in the chemistry of vanadium [1]. They exhibit high catalytic activity in various organic transformations including alkane oxidation [2-10], olefin epoxidation [11-18], aromatization 
of $\alpha, \beta$-unsaturated cyclohexanone derivatives [19,20], alcohol oxidation [21-25], C-C bond cleavage of glycols [26-28], naphthol coupling [29] and $\alpha$-oxidation of hydroxyl esters and amides [30] etc. The use of oxovanadium complexes in the oxidation reactions of various substrates, in particular saturated and unsaturated hydrocarbons is due to the following factors: (a) the ability of vanadium to adopt different coordination numbers (5 and 6), (b) the stability of vanadium in oxidation states +4 and +5 under aerobic conditions, (c) the Lewis acidic nature of the vanadium centers and (d) the high oxophilicity of vanadium.

Our recent studies have shown that oxovanadium(IV) complexes with redox-active diimine ligands exhibit high catalytic activity towards alkanes and alcohols oxygenation with $\mathrm{H}_{2} \mathrm{O}_{2}$ or tert-butyl hydroperoxide in MeCN. In particular, the square-pyramidal oxidovanadium(IV) complex $\left[\mathrm{VOCl}_{2}\right.$ (dpp-bian)] (dpp-bian = bis[N-(2,6-diisopropylphenyl)imino]acenaphthene) [10] and polymeric complexes of general formula $\left[\mathrm{VO}(\mathrm{L}) \mathrm{X}_{2}\right]_{\mathrm{n}}(\mathrm{L}=\mathrm{bpy}$, phen and $\mathrm{X}=\mathrm{Cl}, \mathrm{Br})$ [31] were synthesized and tested as oxidation catalysts. In this framework, we report herein further results on the preparation of a novel octahedral oxidovanadium(IV) complex $\left[\mathrm{VOCl}_{2}(\mathrm{dbbpy})\left(\mathrm{H}_{2} \mathrm{O}\right)\right](\mathbf{1})$, as well as its catalytic properties in the cyclooctene oxidation with tert-butyl hydroperoxide in $\mathrm{CHCl}_{3}$, which is another commonly used solvent for catalyzed oxidations. Careful analysis of the reaction products revealed the presence of side reactions that depend on the solvent nature and purity.

\section{Experimental Section}

\subsection{General procedures}

All synthetic manipulations were carried out in air. Catalytic experiments were carried out in argon. Reagent grade chemicals were obtained from Aldrich and used without further purification. All organic solvents were distilled by standard methods before use.

\subsection{Physical Measurements}

The CHN elemental analysis was performed on a Euro EA 3000 analyzer. The FT-IR spectrum in the range of 4000-400 $\mathrm{cm}^{-1}$ was recorded on a Scimitar FTS 2000 spectrometer. EPR spectra were recorded at the X- and Q- bands at $77 \mathrm{~K}$ and $300 \mathrm{~K}$ on an E-109 Varian spectrometer equipped with an analog-to-digital signal converter and were analyzed and simulated with the EasySpin (Matlab) software package [32].

\subsection{X-ray crystallography}

Single crystals of $\mathbf{1} \cdot 1.5 \mathrm{CH}_{2} \mathrm{Cl}_{2}$ suitable for the $\mathrm{X}$-ray diffraction analysis were obtained by recrystallization from a $\mathrm{CH}_{2} \mathrm{Cl}_{2} / \mathrm{Et}_{2} \mathrm{O}$ mixture. The diffraction data for $\mathbf{1} \cdot 1.5 \mathrm{CH}_{2} \mathrm{Cl}_{2}$ were collected on a Bruker X8 Apex diffractometer with MoK $\alpha$ radiation $(\lambda=0.71073)$ by doing $\varphi$ 
and $\omega$ scans of narrow $\left(0.5^{\circ}\right)$ frames at $150 \mathrm{~K}$. The absorption was empirically corrected using SADABS [33]. Crystallographic data and refinement details for $1 \cdot 1.5 \mathrm{CH}_{2} \mathrm{Cl}_{2}$ are given in Table 1. The structure was solved with SHELXT [34] and refined by full-matrix least-squares cycles against $|F|^{2}$ in anisotropic approximation with SHELXL 2017/1 [35] in ShelXle program [36]. Hydrogen atoms were refined in geometrically calculated positions. The number of highly disordered $\mathrm{CH}_{2} \mathrm{Cl}_{2}$ molecules was found with the SQEEZE procedure [37], which gave $63.5 \mathrm{e}$ in a void with a $154.05 \AA^{3}$ volume. It corresponds to $1.5 \mathrm{CH}_{2} \mathrm{Cl}_{2}$, which has $42 \mathrm{e}$ and a molecular volume of $106 \AA$. The crystallographic data have been deposited in the Cambridge Crystallographic Data Centre under the deposition code CCDC 1945435.

Table 1. Main crystallographic characteristics and X-ray diffraction experimental details for $\mathbf{1} \cdot 1.5 \mathrm{CH}_{2} \mathrm{Cl}_{2}$.

\begin{tabular}{|c|c|}
\hline & $\mathbf{1} \cdot 1.5 \mathrm{CH}_{2} \mathrm{Cl}_{2}$ \\
\hline Chemical formula & $\mathrm{C}_{19.5} \mathrm{H}_{29} \mathrm{Cl}_{5} \mathrm{~N}_{2} \mathrm{O}_{2} \mathrm{~V}$ \\
\hline$M_{\mathrm{r}}$ & 551.65 \\
\hline Crystal system, space group & Orthorhombic, Cmca \\
\hline Temperature (K) & 100 \\
\hline$a, b, c(\AA)$ & $17.8155(8), 11.4397(6), 24.1718(13)$ \\
\hline$V\left(\AA^{3}\right)$ & $4926.3(4)$ \\
\hline$Z$ & 8 \\
\hline Radiation type & Mo $K \alpha$ \\
\hline$\mu\left(\mathrm{mm}^{-1}\right)$ & 0.63 \\
\hline Crystal size (mm) & $0.22 \times 0.20 \times 0.15$ \\
\hline Diffractometer & Bruker X8Apex \\
\hline Absorption correction & $\begin{array}{l}\text { Multi-scan } \\
\text { SADABS (Bruker-AXS, 2004) }\end{array}$ \\
\hline$T_{\min }, T_{\max }$ & $0.596,0.746$ \\
\hline $\begin{array}{l}\text { No. of measured, independent } \\
\text { and } \\
\text { observed }[I>2 \sigma(I)] \text { reflections }\end{array}$ & $11345,2933,2630$ \\
\hline$R_{\text {int }}$ & 0.032 \\
\hline$\theta$ values $\left(^{\circ}\right)$ & $\theta_{\max }=27.6, \theta_{\min }=3.9$ \\
\hline$(\sin \theta / \lambda)_{\max }\left(\AA^{-1}\right)$ & 0.652 \\
\hline Range of $h, k, l$ & $-23 \leq h \leq 17,-10 \leq k \leq 14,-26 \leq l \leq 31$ \\
\hline$R\left[F^{2}>2 \sigma\left(F^{2}\right)\right], w R\left(F^{2}\right), S$ & $0.056,0.152,1.21$ \\
\hline $\begin{array}{l}\text { No. of reflections, parameters, } \\
\text { restraints }\end{array}$ & $2933,121,0$ \\
\hline H-atom treatment & $\begin{array}{l}\text { H atoms treated by a mixture of independent and constrained } \\
\text { refinement }\end{array}$ \\
\hline
\end{tabular}




\begin{tabular}{|l|l|}
\hline Weighting scheme & $\begin{array}{l}w=1 /\left[\sigma^{2}\left(F_{\mathrm{o}}^{2}\right)+(0.0518 P)^{2}+26.942 P\right] \\
\text { where } P=\left(F_{\mathrm{o}}{ }^{2}+2 F_{\mathrm{c}}^{2}\right) / 3\end{array}$ \\
\hline$\Delta \rho_{\max }, \Delta \rho_{\min }\left(\mathrm{e} \AA^{-3}\right)$ & $0.55,-0.54$ \\
\hline
\end{tabular}

\subsection{Synthesis of $\left[\mathrm{V}^{\mathrm{IV}} \mathrm{OCl}_{2}(\mathrm{dbbpy})\left(\mathrm{H}_{2} \mathrm{O}\right)\right](1)$}

To a suspension of $\mathrm{VCl}_{3}(115 \mathrm{mg}, 0.7 \mathrm{mmol})$ in acetonitrile $(14 \mathrm{ml})$ was added 4,4'-di-tertbutyl-2,2'-bipyridine (196 mg, $0.7 \mathrm{mmol}$ ) and the mixture was refluxed for 4 hours in air. The resulting solution was evaporated to dryness and the residue was dissolved in $\mathrm{CH}_{2} \mathrm{Cl}_{2}(7 \mathrm{ml})$. Slow diffusion of an $\mathrm{Et}_{2} \mathrm{O}$ layer into the dichloromethane solution produced green crystals of $\mathbf{1} \cdot 1.5 \mathrm{CH}_{2} \mathrm{Cl}_{2}$. These crystals readily lost part of the co-crystallized solvent when separated from the mother liquor. Anal. Calc. for $\mathrm{C}_{18} \mathrm{H}_{26} \mathrm{Cl}_{2} \mathrm{~N}_{2} \mathrm{O}_{2} \mathrm{~V} \cdot 0.8 \mathrm{CH}_{2} \mathrm{Cl}_{2}$ : C, 45.9; H, 5.7; N, $5.7 \%$. Found: $\mathrm{C}, 45.7 ; \mathrm{H}, 5.6 ; \mathrm{N}, 5.8 \%$. Extensive drying $1 \cdot 1.5 \mathrm{CH}_{2} \mathrm{Cl}_{2}$ under vacuum gave 1. Anal. Calc. for $\mathrm{C}_{18} \mathrm{H}_{26} \mathrm{Cl}_{2} \mathrm{~N}_{2} \mathrm{O}_{2} \mathrm{~V}$ : C, 50.9; H, 6.2; N, $6.6 \%$. Found: C, 50.9; H, 6.4; N, 6.6 \%. Yield: $327 \mathrm{mg}$ (95\%). IR (KBr) v/cm ${ }^{-1}$ : 3440(br.s), 3066(w), 2961(s), 2910(w), 2871(w), 1642(m), 1616(s), 1548(m), 1480(m), 1410(s), 1362(w), 1306(w), 1256(m), 1201(w), 1119(w), 1026(m), 989(s), 901(m), 865(m), 852(m), 746(w), 721(w), 609(m), 560(w).

\subsection{Procedure for the catalyzed epoxidation reaction}

With GC monitoring. Cyclooctene (135 mg, $1.2 \mathrm{mmol}$ ), complex 1 (10 mg, $0.024 \mathrm{mmol}, 2 \%)$, trioxane $(72 \mathrm{mg}, 0.8 \mathrm{mmol})$ and $4 \mathrm{~mL}$ of chloroform were mixed in a Schlenk tube. The mixture was stirred and a first aliquot $(0.1 \mathrm{~mL})$ was withdrawn, before adding the TBHP solution $(0.43$ $\mathrm{mL}, 5.5 \mathrm{M}$ in decane, $2.4 \mathrm{mmol})$. A second aliquot $(0.1 \mathrm{~mL})$ was then rapidly taken. After that the reaction mixture was warmed to $55^{\circ} \mathrm{C}$ with stirring for $5 \mathrm{~h}$. Aliquots were analyzed by GC after quenching the residual TBHP by addition of excess $\mathrm{PPh}_{3}$. A control experiment with GC and ${ }^{31} \mathrm{P}$ NMR showed that the reaction between TBHP and $\mathrm{PPh}_{3}$ is immediate and quantitative to produce $t \mathrm{BuOH}$ and $\mathrm{Ph}_{3} \mathrm{P}=\mathrm{O}$.

With ${ }^{1}$ H NMR monitoring. In a Schlenk flask, 1 (10 mg, $\left.0.024 \mathrm{mmol}\right)$ was dissolved in $4 \mathrm{ml}$ of chloroform. Subsequently, cycloooctene $(160 \mu \mathrm{l}, 1.2 \mathrm{mmol})$ and trioxane $(620 \mu \mathrm{l}, 0.8 \mathrm{mmol}$, internal standard) were added. The mixture was stirred and a first aliquot $(0.1 \mathrm{~mL})$ was withdrawn. Then, $0.43 \mathrm{ml}$ of a decane solution of TBHP (5.5 M, $2.4 \mathrm{mmol})$ were added to the resulting solution. The mixture was stirred at $55^{\circ} \mathrm{C}$ and $0.1 \mathrm{~mL}$ aliquots were periodically withdrawn for the ${ }^{1} \mathrm{H}$ NMR monitoring. With the exception of the first aliquot which does not contain TBHP, all other aliquots were introduced into an NMR tube containing ca. $63 \mathrm{mg}(0.24$ mmol) of triphenylphosphine solubilized in $\mathrm{CDCl}_{3}$ in order to quench the residual TBHP and then directly used for the ${ }^{1} \mathrm{H}$ and ${ }^{31} \mathrm{P}$ analyses. A control experiment showed that the reaction 
between TBHP and $\mathrm{PPh}_{3}$ is immediate and quantitative to produce $t \mathrm{BuOH}$ and $\mathrm{Ph}_{3} \mathrm{P}=\mathrm{O}$ (identified by GC and ${ }^{31} \mathrm{P}$ NMR). Another control experiment was run in the absence of cyclooctene, in order to make sure that trioxane is not altered under the oxidizing conditions, using the solvent peak as internal standard: integration of the chloroform signal at $7.3 \mathrm{ppm}$ and of the trioxane signal at $5.15 \mathrm{ppm}$ showed a constant intensity ratio over a $21 \mathrm{~h}$ period at $55^{\circ} \mathrm{C}$.

\section{Large-scale epoxidation and isolation of the trans-1,2-dichlorocylooctane product.} Cyclooctene (2.07 g, $18.8 \mathrm{mmol})$, complex 1 ( $80 \mathrm{mg}, 0.188 \mathrm{mmol}, 1 \mathrm{~mol} \%)$, and $30 \mathrm{~mL}$ of chloroform were mixed in a Schlenk tube under argon. The mixture was stirred and a TBHP solution $(6.8 \mathrm{~mL}, 5.5 \mathrm{M}$ in decane, $37.6 \mathrm{mmol})$ was added by syringe. The reaction mixture was then warmed to $55^{\circ} \mathrm{C}$ with stirring for $42 \mathrm{~h}$, with GC monitoring, and evaporated to dryness to give an oily residue, which was redissolved in diethyl ether and filtered on a small patch of silica to remove the catalyst. The resulting solution was evaporated again to dryness yielding a yellow oil, which was dissolved in $4 \mathrm{~mL}$ of ethanol. $8 \mathrm{~mL}$ of $2 \mathrm{M} \mathrm{HCl}(16 \mathrm{mmol})$ were added to this solution and the reaction mixture was stirred for $24 \mathrm{~h}$ at room temperature. The organic phase was then extracted by dichloromethane, placed over $\mathrm{Na}_{2} \mathrm{CO}_{3}$, filtered and evaporated. The oily residue was purified by chromatographic separation on a silica column eluting with pentane. A colorless oily pure compound was obtained (yield: $30 \mathrm{mg}, 1 \%$ ) and characterized as trans-1,2-dichlorocyclooctane by NMR analysis. A few other fractions containing trans-1,2dichlorocyclooctane together with other byproducts were also obtained and discarded.

\section{Results and discussion}

\subsection{Synthesis and characterization}

The title complex was synthesized from vanadium(III) chloride $\left(\mathrm{VCl}_{3}\right)$ and 4,4'-di-tertbutyl-2,2'-bipyridine (dbbpy), with concomitant oxidation in air to give the $\{\mathrm{V}=\mathrm{O}\}^{2+}$ moiety, see Scheme 1. The same synthetic procedure was previously used for the preparation of other oxidovanadium(IV) complexes with 2,2'-bipyridine, 1,10-phenathroline [31], bis(N-(2,6diisopropylphenyl)-imino)acenaphthene (dpp-bian) [10], dehydrophenanthroline and diazofluorene ligands [42]. The reaction of $\mathrm{VCl}_{3}$ with 4,4'-di-tert-butyl-2,2'-bipyridine (dbbpy) $\left(1: 1\right.$ molar ratio) in acetonitrile in air results in $\left[\mathrm{VOCl}_{2}(\mathrm{dbbpy})\left(\mathrm{H}_{2} \mathrm{O}\right)\right](\mathbf{1})$ in high yield $(95 \%)$. The complex was isolated as a solvate with $\mathrm{CH}_{2} \mathrm{Cl}_{2}$ molecules $\left(\mathbf{1} \cdot 1.5 \mathrm{CH}_{2} \mathrm{Cl}_{2}\right)$ as confirmed by the $\mathrm{X}$-ray structure data. The isolated crystals easily lose $\mathrm{CH}_{2} \mathrm{Cl}_{2}$ molecules to give $\mathbf{1}$, which is stable in air, both in solution and in the solid state, and is well-soluble in $\mathrm{CH}_{3} \mathrm{CN}, \mathrm{CH}_{2} \mathrm{Cl}_{2}$, $\mathrm{CHCl}_{3}$ and other organic solvents. The same complex was recently used by us as a building block to obtain a binuclear complex $[\mathrm{VO}(\mathrm{dbbpy}) \mathrm{Cl}(\mathrm{Ca}) \mathrm{Cl}(\mathrm{dbbpy}) \mathrm{VO}]$ with bridging chronilate 
$\mathrm{Ca}^{2-}$ [43]. Other previously reported oxidovanadium complexes containing dbbpy ligands are cis- $\left[\mathrm{V}^{\mathrm{IV}} \mathrm{O}(\mathrm{OH})(\mathrm{dbbpy})\right] \mathrm{Y}\left(\mathrm{Y}=\mathrm{BF}_{4}^{-}, \mathrm{SbF}_{6}^{-}\right), c i s-\left[\mathrm{V}^{\mathrm{IV}} \mathrm{O}(\mathrm{F})(\mathrm{dbbpy})_{2}\right] \mathrm{A}\left(\mathrm{A}=\mathrm{BF}_{4}^{-}, \mathrm{ClO}_{4}^{-}\right)$, $\left[\mathrm{V}_{2} \mathrm{O}_{2}(\mu-\mathrm{MeO})_{2}\left(\mu-\mathrm{MO}_{4}\right)_{2}(\mathrm{dbbpy})_{2}\right](\mathrm{M}=\mathrm{Mo}, \mathrm{W}),\left[(\mathrm{VO})_{2}\left(\mu_{2}-\mathrm{SO}_{4}\right)_{2}(\mathrm{dbbpy})_{2}\left(\mathrm{CH}_{3} \mathrm{OH}\right)_{2}\right]$ and $\left[(\mathrm{VO})_{2}\left(\mu_{2}-\mathrm{O}\right)_{2}\left(\mu_{2}-\mathrm{SO}_{4}\right)(\mathrm{dbbpy})_{2}\right][38-41]$.<smiles>[R]c1ccnc(-c2cc([R])ccn2)c1</smiles>

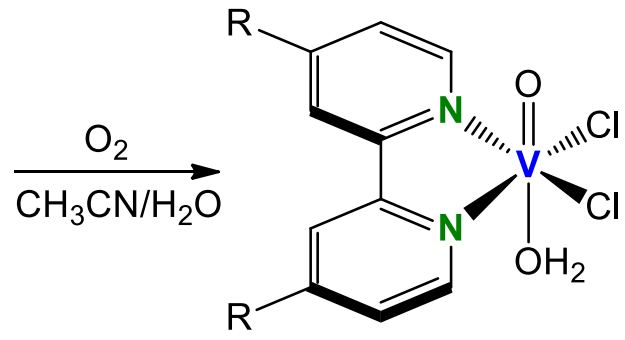<smiles>CC(C)(C)[AlH2][Mg]</smiles>

Scheme 1. Reaction scheme for the synthesis of $\mathbf{1}$

The IR spectrum of 1 shows a strong band at $989 \mathrm{~cm}^{-1}$, assigned to a $\mathrm{V}=\mathrm{O}$ stretching mode in agreement with those reported for other oxidovanadium(IV) complexes [10,44-46]. The broad vibration band at $3440 \mathrm{~cm}^{-1}$ for the $\mathrm{OH}$ group in $\mathrm{H}_{2} \mathrm{O}$ and vibration bands for the $\mathrm{CH}$ group (2871-2961 $\left.\mathrm{cm}^{-1}\right)$ and for the $\mathrm{C}=\mathrm{C}$ and $\mathrm{C}=\mathrm{N}$ groups $\left(1642-1548 \mathrm{~cm}^{-1}\right)$ of the dbbpy ligand (Fig. S1, see ESI) were also observed. A band at $901 \mathrm{~cm}^{-1}$ is assigned to the V-O stretching vibration of the $\mathrm{V}-\mathrm{H}_{2} \mathrm{O}$ moiety.

\subsection{Crystal structure}

Crystals of $1 \cdot 1.5 \mathrm{CH}_{2} \mathrm{Cl}_{2}$ were grown by recrystallization of 1 from a $\mathrm{CH}_{2} \mathrm{Cl}_{2} / \mathrm{Et}_{2} \mathrm{O}$ and were studied by single crystal X-ray diffraction analysis. The molecular structure of $\mathbf{1}$ is represented in Fig. 1. Selected bond distances and angles are given in Table 2. Vanadium(IV) has a distorted octahedral environment. The equatorial plane of the octahedron is defined by two chlorides and two nitrogen atoms of the dbbpy ligand while the oxido and $\mathrm{H}_{2} \mathrm{O}$ ligands occupy the axial positions.

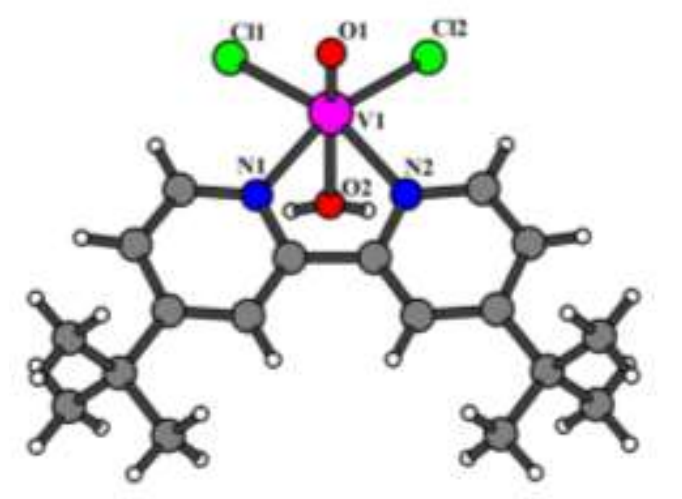

Fig. 1 Molecular structure of $\left[\mathrm{VOCl}_{2}(\mathrm{dbbpy})\left(\mathrm{H}_{2} \mathrm{O}\right)\right]$ in $\mathbf{1} \cdot 1.5 \mathrm{CH}_{2} \mathrm{Cl}_{2}$. 
Table 2. Selected geometric parameters $\left(\AA{ }^{\circ}\right)$ for $\mathbf{1} \cdot 1.5 \mathrm{CH}_{2} \mathrm{Cl}_{2}$

\begin{tabular}{llll}
\hline & $\mathbf{1} \cdot 1.5 \mathrm{CH}_{2} \mathrm{Cl}_{2}$ & $\mathbf{1} \cdot 1.5 \mathrm{CH}_{2} \mathrm{Cl}_{2}$ \\
\hline $\mathrm{V}-\mathrm{O}(1)$ & $1.589(3)$ & $\mathrm{V}-\mathrm{Cl} 1$ & $2.3662(9)$ \\
$\mathrm{V}-\mathrm{O}(2)$ & $2.259(3)$ & $\mathrm{V}-\mathrm{Cl} 2$ & $2.3663(9)$ \\
& & $\mathrm{V}-\mathrm{N}$ & $2.128(3)$ \\
& & $C i s$-angles & \\
$\mathrm{O}(1)-\mathrm{V}-\mathrm{Cl}$ & $98.16(9)$ & $\mathrm{N}(1)-\mathrm{V}-\mathrm{N}(2)$ & $76.14(13)$ \\
$\mathrm{O}(2)-\mathrm{V}-\mathrm{Cl}$ & $84.39(6)$ & $\mathrm{Cl}(1)-\mathrm{V}-\mathrm{Cl}(2)$ & $94.58(4)$ \\
$\mathrm{O}(1)-\mathrm{V}-\mathrm{N}$ & $97.74(12)$ & $\mathrm{N}(1)-\mathrm{V}-\mathrm{Cl}(1)$ & $92.42(7)$ \\
$\mathrm{O}(2)-\mathrm{V}-\mathrm{N}$ & $79.30(10)$ & $\mathrm{N}(2)-\mathrm{V}-\mathrm{Cl}(2)$ & $92.42(7)$ \\
& & $\operatorname{Trans}-\mathrm{angles}$ & \\
& & $\mathrm{O}(1)-\mathrm{V}-\mathrm{O}(2)$ & $176.21(15)$ \\
& & $\mathrm{N}(1)-\mathrm{V}-\mathrm{Cl}(2)$ & $161.52(8)$ \\
& & $\mathrm{N}(2)-\mathrm{V}-\mathrm{Cl}(1)$ & $161.52(8)$ \\
\hline
\end{tabular}

The $\mathrm{V}=\mathrm{O}$ distance of 1.5905(1) $\AA$ is within the 1.56-1.63 $\AA$ range reported for other

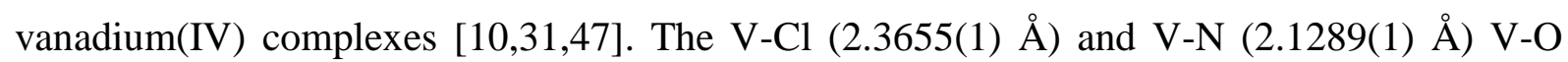
(2.2589(1) $\AA$ ) distances are similar to those found elsewhere [10,31,48-50].

\subsection{EPR spectra}

The EPR spectrum of $\mathbf{1}$ in $\mathrm{CH}_{2} \mathrm{Cl}_{2}$ at room temperature is shown in Fig. 2. The spectrum shows an eight-line pattern due to hyperfine interaction with the ${ }^{51} \mathrm{~V}$ isotope $(\mathrm{I}=7 / 2,100 \%)$, which is typical for oxidovanadium(IV) complexes [10,51]. The $\mathrm{V}^{4+}$ ion has a $4 \mathrm{~d}^{1}$ electronic state with $\mathrm{S}=1 / 2$ and $\mathrm{g}=1.967$. The line splitting varies from $8.98 \mathrm{mT}$ to $11.16 \mathrm{mT}$, and the line half-width varies from $1.28 \mathrm{mT}$ to $2.4 \mathrm{mT}$, due to the vanadium complex mobility in solution and to an incomplete averaging of the $g$ tensor anisotropy. 


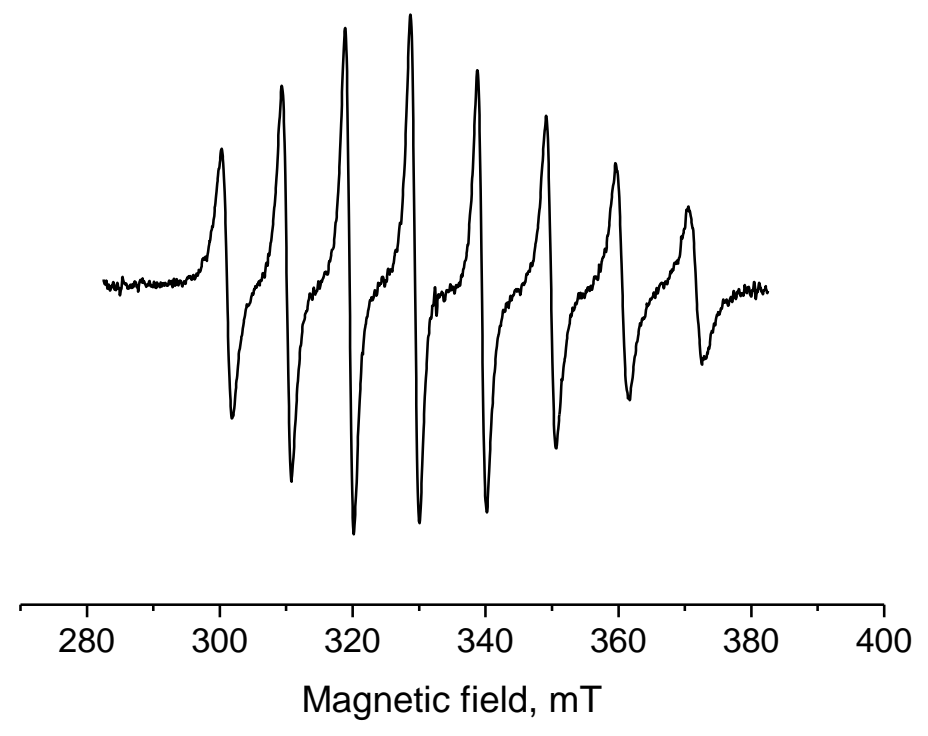

Fig. 2. X-Band CW EPR spectrum of 1 in $\mathrm{CH}_{2} \mathrm{Cl}_{2}$ at $298 \mathrm{~K}$

The EPR spectrum of the frozen solution of $\mathbf{1}$ at $77 \mathrm{~K}$ is shown in Fig. 3. Simulation shows that the experimental spectrum is described by the spin Hamiltonian:

$\mathrm{H}=\mathrm{g}_{\mathrm{xx}} \beta \mathrm{H}_{\mathrm{x}} \mathrm{S}_{\mathrm{x}}+\mathrm{g}_{\mathrm{yy}} \beta \mathrm{H}_{\mathrm{y}} \mathrm{S}_{\mathrm{y}}+\mathrm{g}_{\mathrm{zz}} \beta \mathrm{H}_{\mathrm{z}} \mathrm{S}_{\mathrm{z}}+\mathrm{A}(\mathrm{V})_{\mathrm{xx}} \mathrm{SxIx}+\mathrm{A}(\mathrm{V})_{\mathrm{yy}} \mathrm{S}_{\mathrm{y}} \mathrm{I}_{\mathrm{y}}+\mathrm{A}(\mathrm{V})_{\mathrm{zz}} \mathrm{S}_{\mathrm{z}} \mathrm{I}_{\mathrm{z}}$

with the following parameters: $S=1 / 2, I=7 / 2, g_{x x}=g_{y y}=1.978, g_{z z}=1.945, A_{x x}=A_{y y}=6.5$ $\mathrm{mT}, \mathrm{A}_{\mathrm{zz}}=17.86 \mathrm{mT}$. Similar values were previously reportedfor related oxidovanadium(IV) complexes [10,42]. The EPR spectrum of solid 1 reveals a single-line signal with a half-width width $\left(\Delta \mathrm{H}_{1 / 2}\right)$ of $8.6 \mathrm{mT}$ and $\mathrm{g}=1.967$ due to the exchange interaction between paramagnetic vanadium ions (Fig. S2, see ESI). The analysis of the hyperfine splitting parameters allowed us to estimate the isotropic and anisotropic contributions to the hyperfine interaction with vanadium: $A_{\text {iso }}=10.29 \mathrm{mT}$ and $A_{\text {aniso }}=3.79 \mathrm{mT}$. By using these parameters and assuming a $100 \%$ localization on the $s$ or $d$ orbitals [52], we could estimate the spin density of the unpaired electron on the vanadium atom: $(3.79 / 6.246+10.29 / 148.62) * 100 \%=67.60 \%$. 


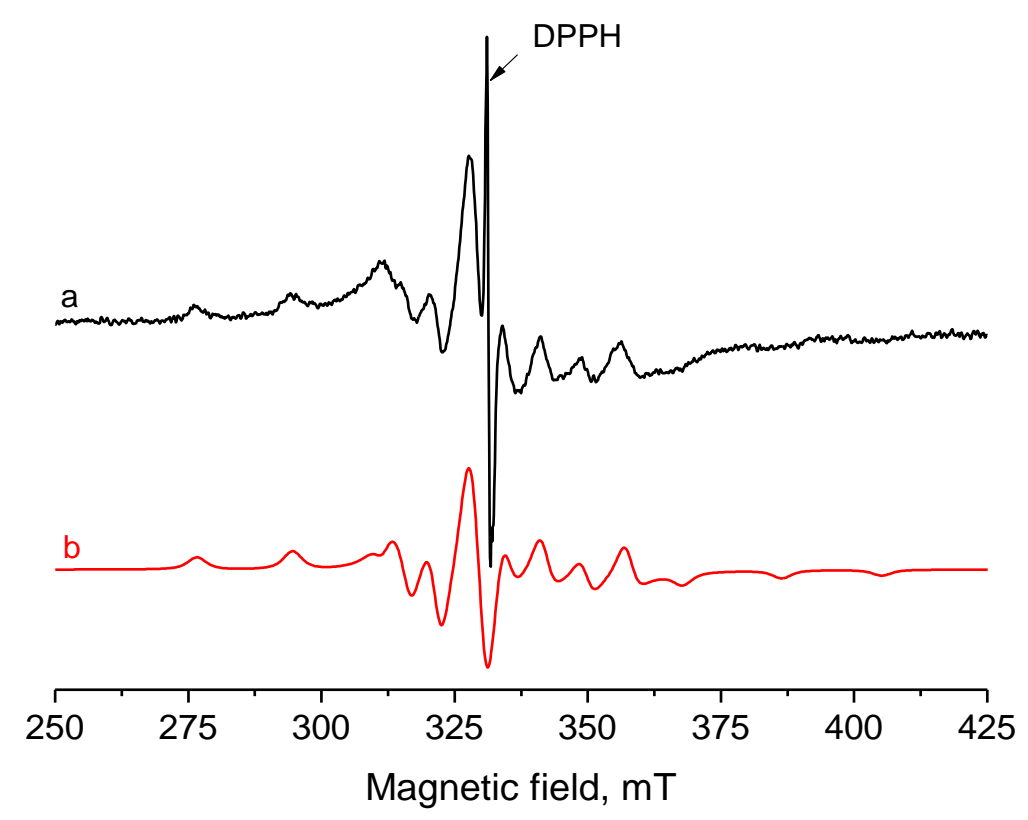

Fig. 3. EPR spectra of 1 in $\mathrm{CH}_{2} \mathrm{Cl}_{2}$ at $77 \mathrm{~K}$. DPPH indicates the single EPR resonance of 2,2diphenyl-1-picrylhydrazyl, which was used as an internal standard, with $\mathrm{g}=2.0036$. $\mathrm{a}-$ experimental, $\mathrm{b}-$ simulated.

\subsection{Cyclooctene epoxidation}

Cyclooctene was chosen as a representative substrate for catalytic studies. It was oxidized by tert-butyl hydroperoxide (TBHP) under mild conditions $\left(55^{\circ} \mathrm{C}\right)$ in the presence of catalytic amounts of complex $\mathbf{1}$ in chloroform. The reaction gave, as expected, cyclooctene epoxide as the main product and traces of the cis-cyclooctan-1,2-diol, whereas no significant amount of the trans-cyclooctan-1,2-diol, which is the expected product of acid-catalyzed epoxide ring opening in the presence of water, was detected. However, a non-negligible amount of a secondary product $\mathbf{2}$ was also noted. The formation of this product did not depend on the method of quenching for the reaction monitoring (vide infra). All products, except for the latter secondary product, were unambiguously identified by the ${ }^{1} \mathrm{H}$ NMR resonance of the methyne $(\mathrm{CH})$ proton and by the comparison of the $\mathrm{GC}$ retention time with genuine standards. The $\mathrm{CH}$ proton of residual cyclooctene yields a multiplet at $\delta 5.6$, whereas that of cyclooctene epoxide resonates at $\delta 2.9$ and that of the cis-diol at $\delta 3.9$. The corresponding proton of the trans-diol is expected at $\delta 3.6 \mathrm{ppm}$ [53], but no significant intensity was observed in this region. The secondary product 2 is characterized by a multiplet at $\delta 4.3$, the shape of which is quite similar to that of the epoxide product. A representative ${ }^{1} \mathrm{H}$-NMR spectrum, recorded after $3.5 \mathrm{~h}$ of 
reaction, is shown in Fig. S3 (ESI). The results of the ${ }^{1} \mathrm{H}$ NMR monitoring are summarized in Fig. 4 (full data in Table S1). The slight erosion of the mass balance, which is accentuated at longer reaction times (see table S1) indicates that other unknown products are also obtained. The catalyst is presumably deactivated during the reaction, since the residual cyclooctene amount stagnates after $5 \mathrm{~h}$.

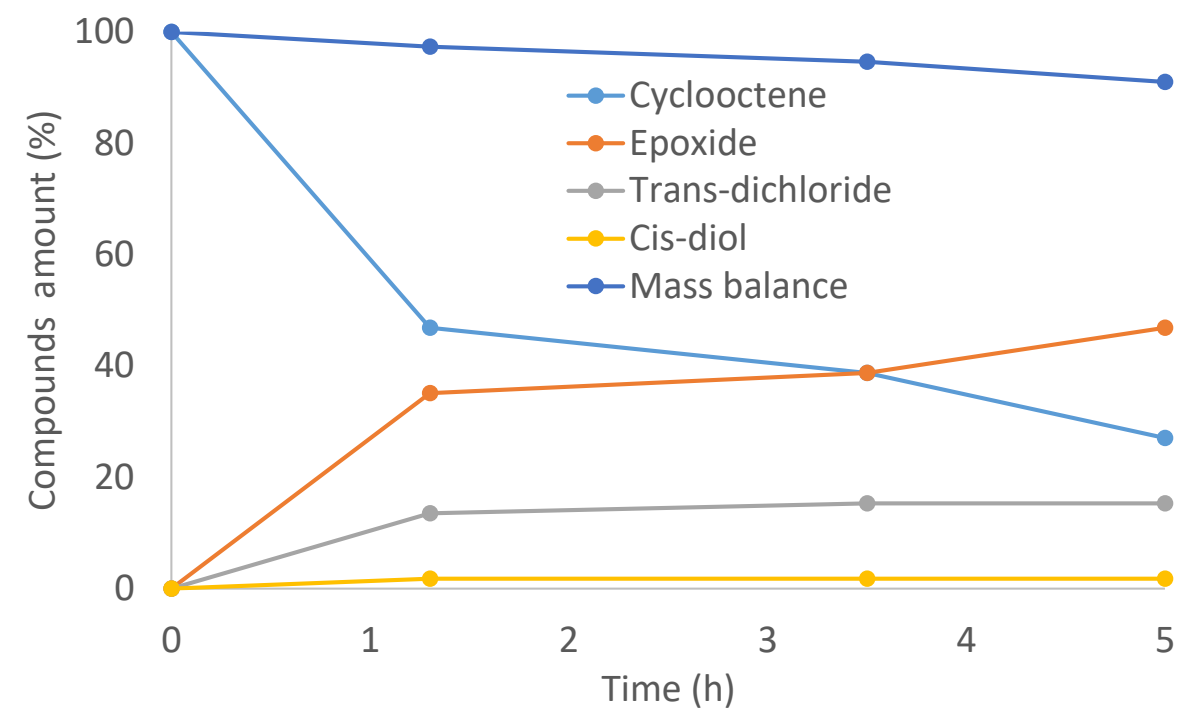

Fig. 4. ${ }^{1} \mathrm{H}$ NMR monitoring of the cyclooctene epoxidation by $\mathrm{TBHP}$ in $\mathrm{CHCl}_{3}$ at $55^{\circ} \mathrm{C}$ catalyzed by compound $\mathbf{1}$.

Identification of the significant secondary product 2 was not easy. The GC-MS analysis revealed a molecular ion corresponding to the $\mathrm{C}_{8} \mathrm{H}_{14} \mathrm{Cl}^{+}$formula that did not match with available library spectra. Unambiguous identification required a large scale catalysis experiment followed by product separation and NMR analysis of the pure product. In this experiment, decane was used as internal standard for a monitoring by GC. The separation was accomplished by quenching the TBHP excess with $\mathrm{PPh}_{3}$, followed by exhaustive hydrolysis of the epoxide product 1 to yield the trans-diol, since the epoxide and compound $\mathbf{2}$ could not be separated in our hands, and by chromatographic separation on a silica column, eluting with pentane, as eluent. Monitoring of the separation step was complicated by the lack of chromophores in both $\mathbf{2}$ and the decane internal standard, but $30 \mathrm{mg}$ of pure isolated compound could eventually be obtained. The hydrocarbons (decane, residual cyclooctene) were eluted first, followed by the desired compound, while the diols remained trapped on the silicagel. Full ${ }^{1} \mathrm{H}$ and ${ }^{13} \mathrm{C}$ analyses of the recovered product allowed its unambiguous identification as trans1,2-dichlorocycooctane. The ${ }^{1} \mathrm{H}$ and ${ }^{13} \mathrm{C}$ NMR data (see SI, Fig. S4 and S5) were identical to 
those reported in the literature for this compound [54]. It is worth pointing out that trans-1,2dichlorocycooctane is the only product of dichlorination. The other isomer, cis-1,2dichlorocycooctane, with an expected signal at $\delta 4.6-4.1 \mathrm{ppm}$ [55], was not observed. This perfect steroselectivity rules out radical dichlorination, which would provide a mixture of diastereoisomers [56]. Because of the trans stereoselectivity, we propose that an electrophilic dichlorination is taking place.

Understanding the origin of chlorine for this reaction is of interest. Formation of $\mathbf{2}$ may be rationalized as the result of 1,2-dichlorination by $\mathrm{HCl}$ (a common contaminant of chloroform) under oxidizing conditions. This transformation occurs without need of metal catalysis and is trans-selective, presumably via the formation of a chloronium intermediate [57]. In order to check this hypothesis, the catalytic oxidation was repeated in a carefully purified chloroform, and also by adding $\mathrm{HCl}$ (as a solution in diethyl ether) but the yield of trans-1,2dichlorocycooctane were not significantly decreased or improved under these conditions. From these results, we conclude that the source of chlorine is not $\mathrm{HCl}$. The only other possible sources of $\mathrm{Cl}$ atoms are compound $\mathbf{1}$ and chloroform itself. The amount of compound $\mathbf{1}$ (2\%) used in the catalytic reactions is not enough to provide the necessary $\mathrm{Cl}$ atoms to produce the observed by-product 2 (23.4\% after $72 \mathrm{~h}$, see table $\mathrm{S} 1)$. We can therefore safely conclude that chloroform (41 equivalents relative to cyclooctene) is the primary source of chlorine atoms. Further studies are necessary to obtain additional insights into the chloroform activation mechanism, but we can tentatively speculate that chloroform may react with TBHP, with or without the intervention of vanadium catalysts, to yield methanol and $t \mathrm{BuOCl}$ or an ether and hypochloric acid, which are possible sources of electrophilic chloronium [57]. To the best of our knowledge, the formation of this by-product has not been previously mentioned, although chloroform is a rather frequently used as solvent for the catalyzed alkene epoxidations with $\mathrm{H}_{2} \mathrm{O}_{2}$ or TBHP $[14,16,17]$.

The above mentioned reaction monitoring by ${ }^{1} \mathrm{H}$ NMR and GC were conducted using $\mathrm{PPh}_{3}$ to quench the excess TBHP, which rapidly transforms the oxidant to $t \mathrm{BuOH}$ and generates $\mathrm{Ph}_{3} \mathrm{P}=\mathrm{O}$, as verified by control experiments and ${ }^{31} \mathrm{P}$ NMR analysis. Preliminary catalytic experiments were also conducted with $\mathrm{MnO}_{2}$ as reagent to quench the excess TBHP. This procedure led to the same product distribution as with the $\mathrm{PPh}_{3}$ quench, but substantial amounts of an additional heavy molecular weight product were also observed in the GC trace. This product could only be detected in very small amounts during the experiments run with a $\mathrm{PPh}_{3}$ quench (see Fig. S6). The GC-MS analysis indicated that this additional product corresponds to 3-trichloromethylcyclooctene. Its formation results from the formal replacement of an allylic hydrogen atom by $\mathrm{CCl}_{3}$, suggesting the involvement of $\mathrm{CCl}_{3}{ }^{\circ}$ radicals. This is corroborated by 
the parallel observation of $\mathrm{C}_{2} \mathrm{Cl}_{6}$ in the $\mathrm{GC}$ spectrum. The production of a large amount of $\mathrm{CCl}_{3}{ }^{*}$ radicals during the TBHP quench with $\mathrm{MnO}_{2}$ can be attributed to the formation of $\mathrm{HO}^{\circ}$ and/or $t \mathrm{BuO}^{\bullet}$ radicals, followed by $\mathrm{H}$ abstraction from the solvent.

Additional investigations were carried out in order to learn more about the catalyst action. When TBHP was added to a solution of complex $\mathbf{1}$, which is pale green, the color turned immediately to violet. The EPR spectrum recorded 10 minutes after the addition of TBHP at $20^{\circ} \mathrm{C}$ shows the overlap of a new 8-line pattern, similar to but different from that of $\mathbf{1}(\mathrm{g}=$ 1.990, A $94 \mathrm{G}$ ) and a strong single line at $\mathrm{g}=2.014$, see Figure 5. The 8-line pattern slowly decreased and completely disappeared, while the second peak still remained after $40 \mathrm{~min}$, and completely disappeared only two days later. In a second similar experiment, carried out at $55^{\circ} \mathrm{C}$, the initial spectrum before the addition of TBHP was identical to that recorded at $20^{\circ} \mathrm{C}$, showing that the precatalyst is stable at this temperature. Addition of TBHP accelerated the degradation. These experiments suggest an immediate reaction between complex $\mathbf{1}$ and TBHP at $20^{\circ} \mathrm{C}$, with the formation of an intermediate $\mathrm{V}^{\mathrm{IV}}$ complex (8-line pattern) and an organic radical (single peak), which then decompose at different rates. The $\mathrm{V}^{\mathrm{IV}}$ intermediate is likely the product of $\mathrm{H}_{2} \mathrm{O}$ substitution by TBHP, by analogy with the intermediate proposed in Mo-catalyzed epoxidation [58]. Its decomposition, in the absence of substrate, presumably yields a $\mathrm{V}^{\mathrm{V}}$ product by homolytic $\mathrm{O}-\mathrm{O}$ cleavage, releasing an $\mathrm{OH}^{*}$ radical (see scheme 2). The latter abstracts the $\mathrm{H}$ atom from the solvent and yields the long-lived $\mathrm{CCl}_{3}{ }^{\circ}$ radical, which presumably accounts for the second observed product in the EPR spectrum. Indeed, as stated above, the formation of 3trichloromethylcylooctene, though in rather small amounts, was also observed in the experiments carried out without a $\mathrm{MnO}_{2}$ quench. It should be underlined that the reactions leading to disappearance of the $\mathrm{V}^{\mathrm{IV}}$ EPR signals are fast at $55^{\circ} \mathrm{C}$ but, when the substrate is present, the catalytic oxidation at this temperature continues at moderate activity for several hours. Thus, the $\mathrm{V}^{\mathrm{V}}$ species produced by oxidation of the $\mathrm{V}^{\mathrm{IV}}$ precatalyst is certainly catalytically active [15]. However, the initially higher catalytic activity may result from either a $\mathrm{V}^{\mathrm{V}}$ or, more likely, a $\mathrm{V}^{\mathrm{IV}}$ species. 


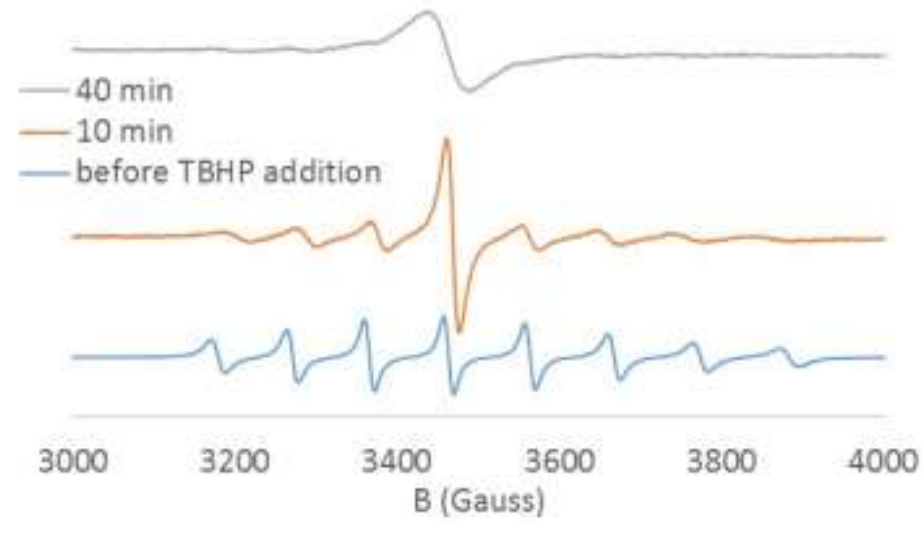

Fig. 5. EPR spectra of the solution of complex 1 in $\mathrm{CHCl}_{3}$ before and after TBHP addition at $20^{\circ} \mathrm{C}$. The spectra recorded 10 and 40 min after the TBHP addition have a vertical scale expanded by a factor of 10 .

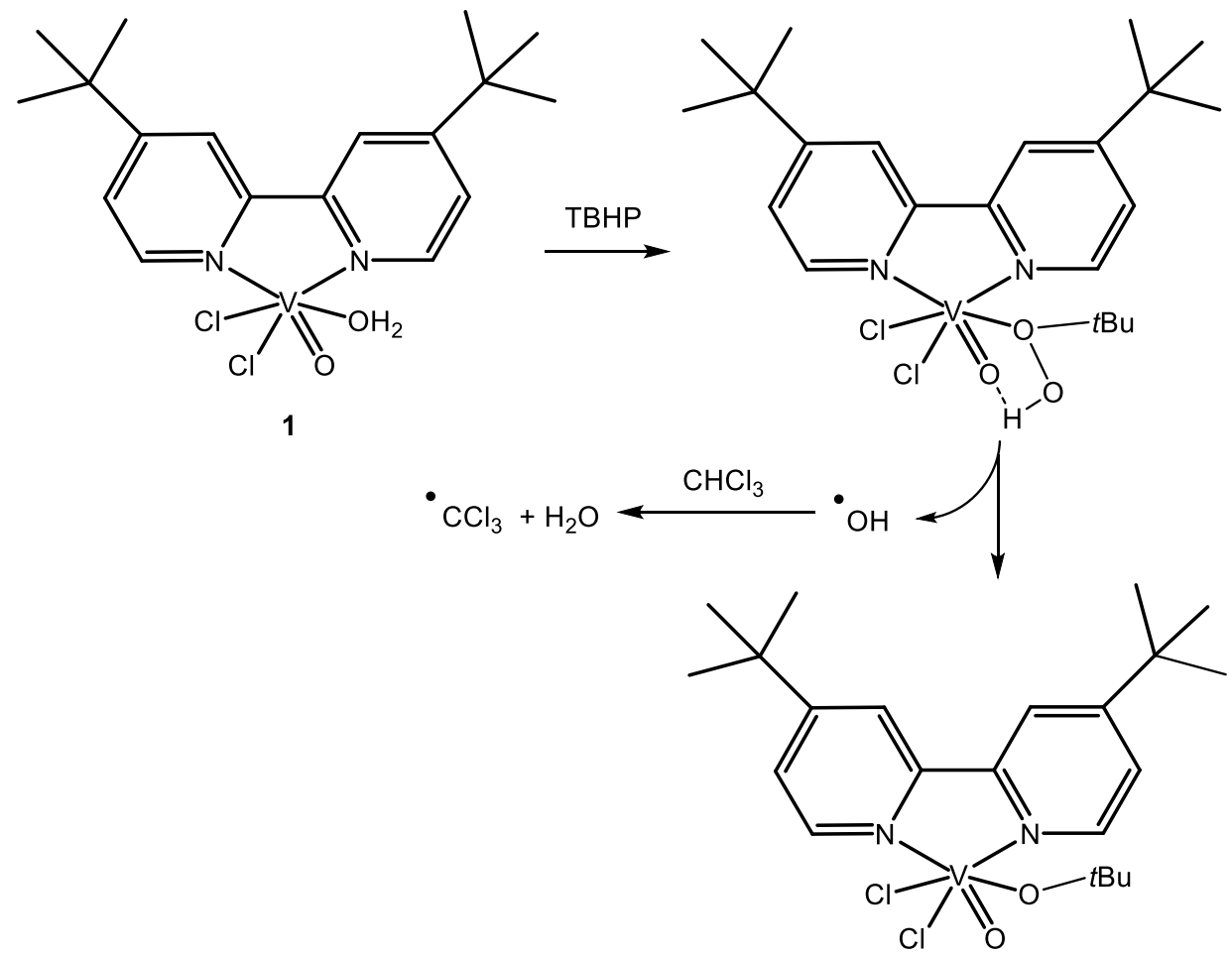

Scheme 2. Proposed action of TBHP on compound 1

\section{Conclusion}

The octahedral oxidovanadium(IV) complex, $\left[\mathrm{VOCl}_{2}(\mathrm{dbbpy})\left(\mathrm{H}_{2} \mathrm{O}\right)\right](\mathbf{1})$, containing the 4,4'-di-tert-butyl-2,2'-bipyridine (dbbpy) ligand was synthesized and characterized using Xray diffraction, IR and EPR spectroscopies. This complex was tested as a catalyst for 
epoxidation of cyclooctene with TBHP in chloroform. A conclusion to be drawn from this study is that one-electron processes occur in the presence of the vanadium(IV) precatalyst, the oxidant and chloroform, generating radical species. In addition, using chloroform in combination with the TBHP oxidant leads to the formation of trans-1,2-dichlorocyclooctane as an unwanted side product of 1,2-dichlorination. It therefore seems wise to avoid the use of chloroform as a solvent in catalyzed oxidations with TBHP (and likely also with $\mathrm{H}_{2} \mathrm{O}_{2}$ ), at least with a vanadium(IV) precatalyst.

\section{Acknowledgements}

We acknowledge the Russian Foundation for Basic Research (grant 18-03-00155-a) and the Centre National de la Recherche Scientifique (CNRS, France) for funding. I. S. F. also thanks the French Embassy in Moscow for a Mechnikov fellowship. 
[1] R.R. Langeslay, D.M. Kaphan, C.L. Marshall, P.C. Stair, A.P. Sattelberger, M. Delferro, Catalytic Applications of Vanadium: A Mechanistic Perspective, Chem. Rev. 119 (2019) 2128-2191. doi:10.1021/acs.chemrev.8b00245.

[2] L. Gonzalez Cuervo, Y.N. Kozlov, G. Süss-Fink, G.B. Shul'pin, Oxidation of saturated hydrocarbons with peroxyacetic acid catalyzed by vanadium complexes, J. Mol. Catal. A Chem. 218 (2004) 171-177. doi:10.1016/J.MOLCATA.2004.04.025.

[3] I. Gryca, K. Czerwińska, B. Machura, A. Chrobok, L.S. Shul'pina, M.L. Kuznetsov, D.S. Nesterov, Y.N. Kozlov, A.J.L. Pombeiro, I.A. Varyan, G.B. Shul'pin, High Catalytic Activity of Vanadium Complexes in Alkane Oxidations with Hydrogen Peroxide: An Effect of 8-Hydroxyquinoline Derivatives as Noninnocent Ligands, Inorg. Chem. 57 (2018) 1824-1839. doi:10.1021/acs.inorgchem.7b02684.

[4] G.B. Shul'pin, C-H functionalization: thoroughly tuning ligands at a metal ion, a chemist can greatly enhance catalyst's activity and selectivity, Dalt. Trans. 42 (2013) 12794. doi:10.1039/c3dt51004b.

[5] M. Sutradhar, N. V. Shvydkiy, M.F.C. Guedes da Silva, M. V. Kirillova, Y.N. Kozlov, A.J.L. Pombeiro, G.B. Shul'pin, A new binuclear oxovanadium(v) complex as a catalyst in combination with pyrazinecarboxylic acid (PCA) for efficient alkane oxygenation by H2O2, Dalt. Trans. 42 (2013) 11791. doi:10.1039/c3dt50584g.

[6] E. V. Gusevskaya, L. Menini, L.A. Parreira, R.A. Mesquita, Y.N. Kozlov, G.B. Shul'pin, Oxidation of isoeugenol to vanillin by the "H2O2-vanadate-pyrazine-2carboxylic acid" reagent, J. Mol. Catal. A Chem. 363-364 (2012) 140-147. doi:10.1016/J.MOLCATA.2012.06.001.

[7] G.B. Shul'pin, Selectivity enhancement in functionalization of $\mathrm{C}-\mathrm{H}$ bonds: A review, Org. Biomol. Chem. 8 (2010) 4217. doi:10.1039/c004223d.

[8] G. Shul'pin, Hydrocarbon Oxygenations with Peroxides Catalyzed by Metal Compounds, Mini. Rev. Org. Chem. 6 (2009) 95-104. doi:10.2174/157019309788167738.

[9] M. V. Kirillova, M.L. Kuznetsov, V.B. Romakh, L.S. Shul'pina, J.J.R. Fraústo da Silva, A.J.L. Pombeiro, G.B. Shul'pin, Mechanism of oxidations with $\mathrm{H} 2 \mathrm{O} 2$ catalyzed by vanadate anion or oxovanadium(V) triethanolaminate (vanadatrane) in combination 
with pyrazine-2-carboxylic acid (PCA): Kinetic and DFT studies, J. Catal. 267 (2009) 140-157. doi:10.1016/J.JCAT.2009.08.006.

[10] I.S. Fomenko, A.L. Gushchin, L.S. Shul'pina, N.S. Ikonnikov, P.A. Abramov, N.F. Romashev, A.S. Poryvaev, A.M. Sheveleva, A.S. Bogomyakov, N.Y. Shmelev, M. V. Fedin, G.B. Shul'pin, M.N. Sokolov, New oxidovanadium( iv ) complex with a BIAN ligand: synthesis, structure, redox properties and catalytic activity, New J. Chem. 42 (2018) 16200-16210. doi:10.1039/C8NJ03358G.

[11] K.I. Smith, L.L. Borer, M.M. Olmstead, Vanadium(IV) and Vanadium(V) Complexes of Salicyladimine Ligands, Inorg. Chem. 42 (2003) 7410-7415. doi:10.1021/IC034640P.

[12] C.J. Chang, J.A. Labinger, H.B. Gray, Aerobic Epoxidation of Olefins Catalyzed by Electronegative Vanadyl Salen Complexes, Inorg. Chem. 36 (1997) 5927-5930. doi:10.1021/IC970824Q.

[13] T. Itoh, K. Jitsukawa, K. Kaneda, S. Teranishi, Vanadium-catalyzed epoxidation of cyclic allylic alcohols. Stereoselectivity and stereocontrol mechanism, J. Am. Chem. Soc. 101 (1979) 159-169. doi:10.1021/ja00495a027.

[14] M. Sedighipoor, A.H. Kianfar, W.A.K. Mahmood, M.H. Azarian, Epoxidation of alkenes by an oxidovanadium(IV) tetradentate Schiff base complex as an efficient catalyst with tert-butyl hydroperoxide, Inorganica Chim. Acta. 457 (2017) 116-121. doi:10.1016/J.ICA.2016.12.018.

[15] V. Conte, A. Coletti, B. Floris, G. Licini, C. Zonta, Mechanistic aspects of vanadium catalysed oxidations with peroxides, Coord. Chem. Rev. 255 (2011) 2165-2177. doi:10.1016/J.CCR.2011.03.006.

[16] M. Bagherzadeh, M. Bahjati, A. Mortazavi-Manesh, Synthesis, characterization and catalytic activity of supported vanadium Schiff base complex as a magnetically recoverable nanocatalyst in epoxidation of alkenes and oxidation of sulfides, $\mathrm{J}$. Organomet. Chem. 897 (2019) 200-206. doi:10.1016/J.JORGANCHEM.2019.06.036.

[17] G. Grivani, G. Bruno, H.A. Rudbari, A.D. Khalaji, P. Pourteimouri, Synthesis, characterization and crystal structure determination of a new oxovanadium(IV) Schiff base complex: The catalytic activity in the epoxidation of cyclooctene, Inorg. Chem. 
Commun. 18 (2012) 15-20. doi:10.1016/J.INOCHE.2011.12.044.

[18] S. Mohebbi, F. Nikpour, S. Raiati, Homogeneous green catalyst for epoxidation of cyclooctene by mono oxovanadium(IV) complexes of N2O2 donate ligand system, J. Mol. Catal. A Chem. 256 (2006) 265-268. doi:10.1016/J.MOLCATA.2006.04.041.

[19] T. Moriuchi, K. Kikushima, T. Kajikawa, T. Hirao, Vanadium-catalyzed oxidative aromatization of 2-cyclohexenones under molecular oxygen, Tetrahedron Lett. 50 (2009) 7385-7387. doi:10.1016/J.TETLET.2009.10.070.

[20] T. Hirao, M. Mori, Y. Ohshiro, VO(OR)Cl2-induced oxidative aromatization of .alpha.,.beta.-unsaturated cyclohexenones, J. Org. Chem. 55 (1990) 358-360. doi:10.1021/jo00288a065.

[21] S.K. Hanson, R. Wu, L.A. "Pete" Silks, Mild and Selective Vanadium-Catalyzed Oxidation of Benzylic, Allylic, and Propargylic Alcohols Using Air, Org. Lett. 13 (2011) 1908-1911. doi:10.1021/ol103107v.

[22] S.K. Hanson, R.T. Baker, J.C. Gordon, B.L. Scott, L.A. "Pete” Silks, D.L. Thorn, Mechanism of Alcohol Oxidation by Dipicolinate Vanadium(V): Unexpected Role of Pyridine, J. Am. Chem. Soc. 132 (2010) 17804-17816. doi:10.1021/ja105739k.

[23] S. Velusamy, T. Punniyamurthy, Novel Vanadium-Catalyzed Oxidation of Alcohols to Aldehydes and Ketones under Atmospheric Oxygen, Org. Lett. 6 (2004) 217-219. doi:10.1021/OL036166X.

[24] Y. Maeda, N. Kakiuchi, S. Matsumura, T. Nishimura, T. Kawamura, S. Uemura, Oxovanadium Complex-Catalyzed Aerobic Oxidation of Propargylic Alcohols, J. Org. Chem. 67 (2002) 6718-6724. doi:10.1021/JO025918I.

[25] J. Rocek, D.E. Aylward, One-electron vs. two-electron oxidations. Vanadium(V) oxidation of cyclobutanols, J. Am. Chem. Soc. 97 (1975) 5452-5456. doi:10.1021/ja00852a021.

[26] G. Zhang, B.L. Scott, R. Wu, L.A. "Pete" Silks, S.K. Hanson, Aerobic Oxidation Reactions Catalyzed by Vanadium Complexes of Bis(Phenolate) Ligands, Inorg. Chem. 51 (2012) 7354-7361. doi:10.1021/ic3007525.

[27] S.K. Hanson, R. Wu, L.A. "Pete" Silks, C $\square \mathrm{C}$ or $\mathrm{C} \square \mathrm{O}$ Bond Cleavage in a Phenolic 
Lignin Model Compound: Selectivity Depends on Vanadium Catalyst, Angew. Chemie Int. Ed. 51 (2012) 3410-3413. doi:10.1002/anie.201107020.

[28] S.K. Hanson, R.T. Baker, J.C. Gordon, B.L. Scott, A.D. Sutton, D.L. Thorn, Aerobic Oxidation of Pinacol by Vanadium(V) Dipicolinate Complexes: Evidence for Reduction to Vanadium(III), J. Am. Chem. Soc. 131 (2009) 428-429. doi:10.1021/ja807522n.

[29] N.B. Barhate, C.-T. Chen, Catalytic Asymmetric Oxidative Couplings of 2-Naphthols by Tridentate N-Ketopinidene-Based Vanadyl Dicarboxylates, Org. Lett. 4 (2002) 2529-2532. doi:10.1021/OL026156G.

[30] A.T. Radosevich, C. Musich, F.D. Toste, Vanadium-Catalyzed Asymmetric Oxidation of $\alpha$-Hydroxy Esters Using Molecular Oxygen as Stoichiometric Oxidant, J. Am. Chem. Soc. 127 (2005) 1090-1091. doi:10.1021/JA0433424.

[31] I. Fomenko, A. Gushchin, P. Abramov, M. Sokolov, L. Shul'pina, N. Ikonnikov, M. Kuznetsov, A. Pombeiro, Y. Kozlov, G. Shul'pin, I.S. Fomenko, A.L. Gushchin, P.A. Abramov, M.N. Sokolov, L.S. Shul'pina, N.S. Ikonnikov, M.L. Kuznetsov, A.J.L. Pombeiro, Y.N. Kozlov, G.B. Shul'pin, New Oxidovanadium(IV) Complexes with 2,2'-bipyridine and 1,10-phenathroline Ligands: Synthesis, Structure and High Catalytic Activity in Oxidations of Alkanes and Alcohols with Peroxides, Catalysts. 9 (2019) 217. doi:10.3390/catal9030217.

[32] S. Stoll, A. Schweiger, EasySpin, a comprehensive software package for spectral simulation and analysis in EPR, J. Magn. Reson. 178 (2006) 42-55. doi:10.1016/J.JMR.2005.08.013.

[33] SHELDRICK, G. M., Program for Empirical Absorption Correction of Area Detector Data, SADABS. (1996). https://ci.nii.ac.jp/naid/10011313791/ (accessed June 16, 2019).

[34] G.M. Sheldrick, SHELXT - Integrated space-group and crystal-structure determination, Acta Crystallogr. Sect. A Found. Adv. 71 (2015) 3-8. doi:10.1107/S2053273314026370.

[35] G.M. Sheldrick, Crystal structure refinement with SHELXL, Acta Crystallogr. Sect. C Struct. Chem. 71 (2015) 3-8. doi:10.1107/S2053229614024218. 
[36] C.B. Hübschle, G.M. Sheldrick, B. Dittrich, ShelXle : a Qt graphical user interface for SHELXL, J. Appl. Crystallogr. 44 (2011) 1281-1284.

doi:10.1107/S0021889811043202.

[37] A.L. Spek, IUCr, PLATON SQUEEZE: a tool for the calculation of the disordered solvent contribution to the calculated structure factors, Acta Crystallogr. Sect. C Struct. Chem. 71 (2015) 9-18. doi:10.1107/S2053229614024929.

[38] G.D. Triantafillou, E.I. Tolis, A. Terzis, Y. Deligiannakis, C.P. Raptopoulou, M.P. Sigalas, T.A. Kabanos, Monomeric Oxovanadium(IV) Compounds of the General Formula cis-[V IV $(=\mathrm{O})(\mathrm{X})(\mathrm{LNN}) 2]+/ 0\left\{\mathrm{X}=\mathrm{OH}-, \mathrm{Cl}-, \mathrm{SO} 42-\right.$ and $\mathrm{LNN}=2,2^{\prime}-$ Bipyridine (Bipy) or 4,4'-Disubstituted Bipy \}, Inorg. Chem. 43 (2004) 79-91. doi:10.1021/ic034440d.

[39] S.S. Passadis, C. Tsiafoulis, C. Drouza, A.C. Tsipis, H.N. Miras, A.D. Keramidas, T.A. Kabanos, Synthesis, Bonding, and Reactivity of Vanadium(IV) Oxido-Fluorido Compounds with Neutral Chelate Ligands of the General Formula cis[VIV(=O)(F)(LN-N)2]+, Inorg. Chem. 55 (2016) 1364-1366. doi:10.1021/acs.inorgchem.5b02895.

[40] S. Kodama, A. Nomoto, S. Yano, M. Ueshima, A. Ogawa, Novel heterotetranuclear V 2Mo 2 or V 2W 2 complexes with 4,4'-Di- tert -butyl-2,2'-bipyridine: Syntheses, crystal structures, and catalytic activities, Inorg. Chem. 50 (2011) 9942-9947. doi:10.1021/ic2009094.

[41] E.S. Bazhina, M.E. Nikiforova, G.G. Aleksandrov, N.N. Efimov, H.A. Ugolkova, O.M. Nikitin, T. V. Magdesieva, A.S. Bogomyakov, V. V. Minin, A.A. Sidorov, V.M. Novotortsev, I.L. Eremenko, New sulfate-bridged dinuclear oxidovanadium complexes, Inorganica Chim. Acta. 392 (2012) 192-198. doi:10.1016/j.ica.2012.06.001.

[42] Y.S. Fomenko, A.L. Gushchin, A. V. Tkachev, E.S. Vasilyev, P.A. Abramov, V.A. Nadolinny, M.M. Syrokvashin, M.N. Sokolov, Fist oxidovanadium complexes containing chiral derivatives of dihydrophenanthroline and diazafluorene, Polyhedron. 135 (2017) 96-100. doi:10.1016/J.POLY.2017.07.003.

[43] I.S. Fomenko, V.A. Nadolinnyi, N.N. Efimov, V. V. Kokovkin, A.L. Gushchin, 
Binuclear Oxovanadium(IV) Complex with the Bridging Chloranilate Ligand: Synthesis and Magnetic Properties, Russ. J. Coord. Chem. 45 (2019) 776-781.

[44] U. Das, P. Pattanayak, M.K. Santra, S. Chattopadhyay, Synthesis of new oxidovanadium complexes: catalytic properties and cytotoxicity, J. Chem. Res. 42 (2018) $57-62$.

[45] S. Menati, H.A. Rudbari, M. Khorshidifard, F. Jalilian, A new oxovanadium(IV) complex containing an O,N-bidentate Schiff base ligand: Synthesis at ambient temperature, characterization, crystal structure and catalytic performance in selective oxidation of sulfides to sulfones using $\mathrm{H} 2 \mathrm{O} 2$ under solvent-free conditions, J. Mol. Struct. 1103 (2016) 94-102. doi:10.1016/J.MOLSTRUC.2015.08.060.

[46] G.D. Triantafillou, E.I. Tolis, A. Terzis, Y. Deligiannakis, C.P. Raptopoulou, M.P. Sigalas, T.A. Kabanos, Monomeric Oxovanadium(IV) Compounds of the General Formula cis-[VIV $(\mathrm{O})(\mathrm{X})(\mathrm{LNN}) 2]+/ 0\left\{\mathrm{X}=\mathrm{OH}-, \mathrm{Cl}-, \mathrm{SO} 42-\right.$ and $\mathrm{LNN}=2,2^{4}$ Bipyridine (Bipy) or 4,4`-Disubstituted Bipy\}, Inorg. Chem. 43 (2004) 79-91. doi:10.1021/IC034440D.

[47] W.A. Nugent, J.M. Mayer, Metal-Ligand Multiple Bonds, New York, 1988.

[48] Y. Dong, R.N. Krishna, E. Sudbeck, F.M. Uckun, Synthesis, X-ray structure, and antileukemic activity of oxovanadium(IV) complexes, J. Inorg. Biochem. 78 (2000) 321330. doi:10.1016/S0162-0134(00)00060-X.

[49] A.E. King, M. Nippe, M. Atanasov, T. Chantarojsiri, C.A. Wray, E. Bill, F. Neese, J.R. Long, C.J. Chang, A Well-Defined Terminal Vanadium(III) Oxo Complex, Inorg. Chem. 53 (2014) 11388-11395. doi:10.1021/ic5010177.

[50] C.R. Waidmann, A.G. DiPasquale, J.M. Mayer, Synthesis and Reactivity of OxoPeroxo-Vanadium(V) Bipyridine Compounds, Inorg. Chem. 49 (2010) 2383-2391. doi:10.1021/ic9022618.

[51] A. Apostolopoulou, M. Vlasiou, P.A. Tziouris, C. Tsiafoulis, A.C. Tsipis, D. Rehder, T.A. Kabanos, A.D. Keramidas, E. Stathatos, Oxidovanadium(IV/V) Complexes as New Redox Mediators in Dye-Sensitized Solar Cells: A Combined Experimental and Theoretical Study, Inorg. Chem. 54 (2015) 3979-3988. doi:10.1021/acs.inorgchem.5b00159. 
[52] J.. Morton, K.. Preston, Atomic parameters for paramagnetic resonance data, J. Magn. Reson. 30 (1978) 577-582. doi:10.1016/0022-2364(78)90284-6.

[53] M.R. Bukowski, P. Comba, A. Lienke, C. Limberg, C. Lopez de Laorden, R. MasBallesté, M. Merz, L. Que, Catalytic Epoxidation and 1,2-Dihydroxylation of Olefins with Bispidine-Iron(II)/H2O2 Systems, Angew. Chemie Int. Ed. 45 (2006) 3446-3449. doi:10.1002/anie.200504357.

[54] A. Podgoršek, M. Jurisch, S. Stavber, M. Zupan, J. Iskra, J.A. Gladysz, Synthesis and Reactivity of Fluorous and Nonfluorous Aryl and Alkyl Iodine(III) Dichlorides: New Chlorinating Reagents that are Easily Recycled using Biphasic Protocols, J. Org. Chem. 74 (2009) 3133-3140. doi:10.1021/jo900233h.

[55] A. Kohda, K. Ueda, T. Sato, Metal-catalyzed organic photoreactions. One-step synthesis of chlorinated ketones from olefins by photooxidation in the presence of iron(III) chloride, J. Org. Chem. 46 (1981) 509-515. doi:10.1021/jo00316a007.

[56] N. Fu, G.S. Sauer, S. Lin, Electrocatalytic Radical Dichlorination of Alkenes with Nucleophilic Chlorine Sources, J. Am. Chem. Soc. 139 (2017) 15548-15553. doi:10.1021/jacs.7b09388.

[57] N.B. Barhate, A.S. Gajare, R.D. Wakharkar, A. V. Bedekar, Simple and practical halogenation of arenes, alkenes and alkynes with hydrohalic acid/H2O2 (or TBHP), Tetrahedron. 55 (1999) 11127-11142. doi:10.1016/S0040-4020(99)00628-6.

[58] J. Morlot, N. Uyttebroeck, D. Agustin, R. Poli, Solvent-Free Epoxidation of Olefins Catalyzed by "[ $\mathrm{MoO}_{2}$ (SAP)]": A New Mode of tert -Butylhydroperoxide Activation, ChemCatChem. 5 (2013) 601-611. doi:10.1002/cctc.201200068. 